\title{
El estrés laboral desde una perspectiva relacional. Un modelo interpretativo
}

\author{
Work Stress from a Relational Perspective. \\ An Interpretive Model
}

DOI: $10.22380 / 2539472 X .802$

\author{
Josefina Ramírez Velázquez \\ Escuela Nacional de Antropología e Historia, México
}

\begin{abstract}
RESUMEN
El creciente interés por el estrés laboral en países en desarrollo revela las múltiples problemáticas de orden teórico, conceptual y metodológico para su explicación. Existe una gran cantidad de modelos analíticos de estrés y de técnicas para su medición que no alcanzan a comprender los procesos de significación que producen los conjuntos de trabajadores - matizados por contextos culturales laborales específicos-, y que ayudan a explicar su expresión diferencial. Este artículo considera la relevancia de una antropología reflexiva y muestra la trayectoria que seguí en la configuración del modelo interpretativo de estrés en una investigación etnográfica sobre el estrés de operadoras telefónicas en México.
\end{abstract}

Palabras claves: modelo interpretativo de estrés, perspectiva relacional, estrés como metáfora, operadoras telefónicas.

\begin{abstract}
The growing interest in work stress in developing countries reveals the multiple theoretical, conceptual and methodological challenges for its explanation. There are many existing analytical models of stress and measurement techniques that fail to understand the processes of meaning produced by sets of workers - nuanced by specific labor cultural contexts-which help explain their differential expression. This article takes into account the relevance of a reflexive anthropology. It shows the path that I followed in the configuration of an interpretive model of stress resulting from an ethnographic research on stress among telephone operators in Mexico.
\end{abstract}

Keywords: interpretive stress model, relational perspective, stress as metaphor, telephone operators.

Doctora en Antropología del Centro de Investigaciones y Estudios Superiores en Antropología Social (Ciesas). Profesora e investigadora del Posgrado de Antropología Física de la Escuela Nacional de Antropología e Historia (ENAH). jos.ramirez.velazquez@gmail.com / https://orcid. org/0000-0002-5719-2889 


\section{Introducción}

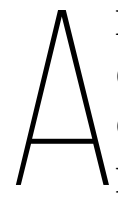

l finalizar el siglo pasado inicié una investigación sobre estrés laboral, considerando que los datos empíricos que había venido construyendo en investigaciones previas con diversos grupos de trabajadores estaban poniendo en el centro de mis inquietudes el malestar psicoemocional de los trabajadores como el eje de sus principales problemáticas de salud. Sin embargo, no advertía aún las características propias del ámbito laboral, su asociación con el ausentismo, la expresión de diversos padecimientos y la escasa atención médica legal que, en circunstancias particulares, requiere el reconocimiento de una enfermedad derivada del trabajo. La recurrente mención de trabajadores mineros, petroleros y obreras de la maquila sobre su situación cotidiana laboral, definida por angustia, tensión, nervios, ansiedad y enojo, me impulsó, sin duda, a poner atención a un dominio analítico poco atendido por la antropología, la dimensión emocional de la enfermedad (Ramírez 2012), que pronto tuvo como categoría orientadora del análisis el estrés.

Antes de la década de los noventa, los estudiosos del mundo laboral en México no se referían al estrés, posiblemente por la tendencia a usar modelos unicausales, medibles y comprobables que suelen focalizar exclusivamente el agente nocivo observable, porque produce señales y síntomas, y a individualizar el riesgo sin problematizar los complejos procesos sociales, culturales y políticos que determinan formas particulares de vivir, padecer y enfermar (Ramírez 2011a). No obstante, algunos estudiosos empezaron a considerar aquellas situaciones cotidianas laborales, analizándolas a partir de la noción de fatiga laboral o desgaste obrero (Laurell y Márquez 1983; Laurell y Noriega 1989). En los albores del siglo XXI se incrementó el número de investigadores interesados en explicar los riesgos y exigencias de un determinado proceso de trabajo, que da lugar a alteraciones fisiológicas y psíquicas de los trabajadores, y se empezó a utilizar el concepto de estrés, entendido como pérdida de la capacidad efectiva o potencial psicológica y psíquica que en las condiciones de producción capitalista es mayor que la reposición y el desarrollo de las capacidades. Es decir, como elemento explicativo de la relación entre el proceso de trabajo y la enfermedad psíquica y psicosomática (Ramírez 2008).

La revisión acuciosa que realicé para la configuración del estado del arte sobre el estrés laboral desde el ámbito antropológico me mostró un panorama complejo. En primer lugar, el estrés ha sido y sigue siendo patrimonio analítico de la biomedicina, la psicología y la psiquiatría y, aunque las estrategias para su estudio se han diversificado mediante múltiples modelos explicativos, la 
tendencia que subyace revela una orientación biologicista, psicologista e individualizada que ha sido cuestionada por varios autores, sobre todo de las ciencias sociales $^{1}$. En segundo lugar advertí que, iniciado este milenio, los referentes empíricos sobre el estrés eran casi inexistentes, por lo cual aún seguíamos sin saber cuáles eran y siguen siendo los grupos vulnerables, cómo se expresa el estrés en cada grupo, cuál es su causalidad estructural y, lo más importante, cómo lo abordaban las diversas investigaciones en términos de orientación conceptual, teórica y metodológica (Ramírez 2010).

Uno de los principales dilemas en el estudio del estrés deriva precisamente del orden conceptual y metodológico. Esta idea fue expuesta de manera crítica desde hace más de tres décadas ${ }^{2}$ por Young (1980) quien, tras analizar los diferentes instrumentos de medición con los cuales se estudian los estresores o eventos de vida estresantes ${ }^{3}$ — que se supone dan cuenta del estrés-, mostró de manera contundente que dichos instrumentos, más que develar la experiencia y perspectiva del sujeto estresado, reflejan el sistema de referencias y creencias del investigador impuestas sobre un sujeto considerado ahistórico y descontextualizado. Una de sus nociones más reveladoras es que

[...] el conocimiento que han producido los investigadores de estrés es conocimiento convencional que está "naturalizado", es decir localizado en la naturaleza en lugar de en la sociedad o la cultura, y "somatizado”, es decir localizado en el individuo y no en sus relaciones sociales. $(1980,140)$

Con este y otros razonamientos señalados por varios autores (Brief y Nord 1990; Lazarus 1999; Pollock 1984), emanados de la exigencia de explicar el estrés más allá de una lista de posibles eventos estresantes analizados con escalas de

1 A partir de la configuración del estado del arte sobre el tema (Ramírez 2010) generé las principales líneas argumentales, teniendo como orientación un análisis paradigmático que me permitió ubicar teórica, conceptual y metodológicamente el estudio del estrés, y subrayar la necesidad de poner atención a su definición y los factores que lo componen, así como a la creación de un estudio relacional y complementario multiepistémico, multiteórico y multimetodológico (Ramírez 2014a).

2 No obstante, dicho análisis sigue teniendo vigencia, ya que pocas cosas han cambiado en la configuración de los modelos de estrés generados desde la psicología, la biomedicina e incluso la sociología.

3 De manera muy general mencionaré que el estudio del estrés a través del análisis de eventos de vida estresantes, considerado como estrés agudo, fue profundamente criticado por Young (1980), Pollock (1988) y Dressler (1996), entre otros autores. Ellos afirmaban que dicho análisis se puede derrumbar porque no tiene en cuenta el hecho de que la naturaleza de un evento de vida estresante no puede definirse de antemano, ya que no tiene existencia independiente; en consecuencia, el evento estresante depende del significado que el actor social elabora. Además, se mencionó la creciente importancia del estrés crónico que hacía referencia a aquellas pequeñas o grandes dificultades cotidianas relacionadas con los roles sociales (Gottlieb 1997), ya fuera en el trabajo o en la familia. 
medición del tipo Likert, puse el énfasis en la importancia del significado que los actores involucrados les dan a los eventos. Esta idea tenía como base la noción fundante que ya venía elaborando en el marco de la antropología física para el estudio crítico del cuerpo como sujeto y como agente (Ramírez 2012). En el reconocimiento del cuerpo como sujeto productor de sentido emergió la posibilidad de estudiar a los trabajadores ${ }^{4}$, ya que estos elaboran ideas, explicaciones, significados, metáforas y prácticas sobre su cuerpo y su experiencia, pero también sobre sus circunstancias laborales, develando así la importancia del contexto que provee la lógica que les da sentido a tales elaboraciones (Ramírez 2007a).

Con estas orientaciones, la investigación sobre el estrés laboral a la que aludí en un inicio se centró en describir y analizar los diferentes procesos mediante los cuales un grupo de operadoras telefónicas "identifica, describe, denomina y maneja determinado espectro de síntomas físicos y estados emocionales bajo la noción de estrés”. La idea de la que partí fue que el estrés es una construcción sociocultural, es decir, una expresión comprometida en marcos culturales e ideológicos. Esto se refiere a que tiene un significado y un uso social, y por tal razón debe ser analizado desde el significado atribuido por los actores sociales. Desde esta perspectiva, la indagación se guio por el paradigma interpretativo centrado en el significado sociocultural y la indisoluble relación entre el actor y el contexto. Esta propuesta, que implica una perspectiva constructivista, anuncia la importancia de comprender la experiencia laboral, el malestar, el padecimiento o la enfermedad laboral desde el punto de vista del actor, es decir, a través de actividades interpretativas (Ramírez 2010).

\section{Las operadoras telefónicas como productoras de sentido}

La elección de las operadoras con quienes realicé la investigación surgió en una suerte de contraste ${ }^{5}$. Por un lado, debido a la inexistencia de un dato duro que me

4 Debido a que la RCA se rige por las normas de la RAE, en este artículo se omitió el uso de lenguaje incluyente, aunque su autora mantiene una perspectiva de género inclusiva. [N. de la e.].

5 Para conocer con detalle las formas de selección del grupo y la etnografía generada durante cerca de un año de trabajo de campo, véase Ramírez (2010). El texto expone los cambios generados en el ámbito de la telefonía, del sindicato, de sus agremiados y, particularmente, la propia voz y experiencia de doce telefonistas desde una cierta densidad etnográfica, producida en el centro de tráfico más antiguo de Telmex, llamado San Juan. 
advirtiera cuáles eran los conjuntos sociales más afectados por situaciones de estrés. Por el otro, a causa de las expresiones que ocurrieron en la vida cotidiana a través de la manifestación política de organizaciones de mujeres, activistas sindicales y académicas, quienes se dieron a la tarea de revelar las problemáticas de estrés de diversos grupos de trabajadoras. Así, junto a la denuncia e identificación del hostigamiento sexual y de los efectos del cambio tecnológico, apareció la urgencia de reconocer el estrés como una enfermedad contemporánea y específica de mujeres que trabajan ${ }^{6}$.

Mi interés por el estudio del estrés de operadoras telefónicas surgió al tratar de explicar esta manifestación política y comprender el sentido que este grupo de mujeres le estaba otorgando al estrés en la exigencia de que se reconociera como una enfermedad profesional. Tal postura constituyó un hecho social de suma importancia que requería ser descifrado: ¿qué significa este reconocimiento? y ¿qué significa el estrés y para quién? fueron las primeras preguntas que orientaron la intención de entenderlo desde el significado social, y en particular desde la experiencia del grupo de operadoras telefónicas. A partir de ello desarrollé una amplia investigación cuyo objetivo central fue detallar y analizar los diferentes procesos por medio de los cuales ellas identifican, describen, denominan y manejan un espectro de síntomas físicos y estados emocionales bajo la noción de estrés.

Al definir a los trabajadores como actores sociales y productores de sentido que luchan constantemente con múltiples demandas que surgen tanto en el ámbito laboral como en el extralaboral, abrí la posibilidad de comprender el estrés ya no como evento estático — circunscrito al trabajo- sino como proceso (Dressler 1996; Lazarus 1999; Pearlin 2010; Pearlin, Mckean y Skaff 1996), cuya expresión diferencial por género, generación, estratificación social y etnia contribuiría a entender los saberes y las prácticas locales, así como a evitar la generalización y homogenización que se producen desde perspectivas cuantitativas.

La concepción del estrés como proceso visibilizó la necesaria relación entre contextos significantes como el ámbito laboral y el familiar, entendidos como un continuum, es decir, como procesos articulados desde los cuales los individuos rigen sus respuestas emocionales y guían sus opciones y acciones, a partir del valor y el significado que les adjudiquen a tales espacios, ya que cambian en

6 A finales de 1999, en la Ciudad de México tuvo lugar un movimiento importante en la Cámara de Diputados y de acciones sindicales lideradas por Rosario Ortiz, militante telefonista y dirigente de la Red de Mujeres Sindicalistas, con el interés de que se reconociera el estrés como enfermedad profesional para ciertos grupos de mujeres trabajadoras (obreras de la maquila, operadoras telefónicas, empleadas de bancos y taquilleras del metro). Para ampliar, véase reportaje en http://www.cimac.org.mx/noticias, del 14 de junio del 2004. 
el tiempo (Eckenrode y Gore 1990; Kohn 1995). Teórica y empíricamente, asumí que el estrés no se podía seguir analizando exclusivamente con referencia al ámbito laboral, ya que los procesos de significación no se dan solo en el trabajo sino también en la familia (Brief y Nord 1990).

\section{El estrés como evento significativo}

Uno de los principales soportes teóricos del estudio del estrés consideró que la enfermedad, además de una construcción biomédica, es un hecho cultural porque representa y expresa. También es un producto sociohistórico susceptible de conocerse a través de actividades interpretativas. En consecuencia, la principal labor fue develar los significados que subyacen al estrés, toda vez que admití que las relaciones sociales, la cultura y la ideología se manifiestan y se reproducen en representaciones de padecimientos y enfermedad (Ramírez 2010). En este sentido, supuse que la noción de estrés encerraba experiencias distintas que referirían a contextos específicos y a toda una riqueza semántica con la que a menudo se expresan los malestares de un cuerpo sentipensante. Una de mis principales inquietudes fue develar dicha riqueza semántica, por lo cual centré mi mirada en la articulación de las sensaciones físicas y los estados emocionales como categorías analíticas y en las diversas descripciones que las operadoras usaron para explicarlas ${ }^{7}$. Estas afirmaciones tienen tras de sí una idea fundante en antropología según la cual no existe actor social sin contexto; esta es una de las principales diferencias entre los modelos biopsicológicos del estrés y mi propuesta, que destaca un modelo interpretativo de este.

\section{El estrés como metáfora}

Decidí abordar el estrés como metáfora para mostrar, en contraposición a la exigencia de objetivar el estrés, una noción que lo ubicara en el mundo subjetivo, en otras palabras, en el de la producción significativa de la vida. La metáfora es esa noción que, al crear nuevo sentido a partir de otro equivalente, permite com-

7 Para ampliar la descripción y explicación de las sensaciones físicas y estados emocionales que configuran el estrés desde el punto de vista de las operadoras, véase Ramírez (2007). 
prender la parte insensata e indecible del padecimiento o la enfermedad, y dar coherencia, explicar y delimitar el origen, la causa o el desarrollo de las cosas y de los comportamientos humanos que de otra manera serían radicalmente inaprehensibles (Ramírez 2010, 45). Lo hice también de forma provocadora, pues en el medio laboral se exige objetividad frente a la enfermedad, la interacción social y el trabajo, y mirar el estrés desde la producción metafórica de los actores permitía develar la realidad social, cultural e ideológica, que a menudo aparece opacada en los modelos cuantitativos de estrés.

Con estas afirmaciones aclaré mi postura ante el grupo de operadoras, quienes me solicitaban una investigación que mostrara con claridad que el estrés era una enfermedad profesional. Cuestión compleja que desde mi perspectiva admitiría, en principio, la monetarización del riesgo, dejando de lado algo que a todas luces es central para su explicación, esto es, comprender las causas y los procesos que subyacen al estrés ${ }^{8}$. En este texto me propuse hacerlos visibles mediante el armado de un modelo analítico.

A diferencia de numerosas perspectivas analíticas que eluden una definición de estrés anteponiendo modelos elaborados exprofeso para correlacionar variables, el proceso constructivo que seguí reflejó mi propia noción de estrés que lo considera como una construcción social, es decir, que su constitución es producto de la relación generada por los actores sociales. En este sentido, si bien asumo que la noción de estrés es una elaboración del saber profesional de la biomedicina y la psicología que describen, mediante diversos indicadores, la reacción neurohormonal y psicológica de un individuo frente a una amplia variedad de estímulos medioambientales, constituye simultáneamente una metáfora que los conjuntos sociales manejan y aplican para explicar síntomas físicos, así como situaciones y relaciones en las que se encuentran inmersos.

La perspectiva relacional que propongo asume que las representaciones y prácticas de estrés se crean en una compleja concepción construida desde la experiencia corporal, que se extiende en un andamiaje de metáforas, dependiendo del contexto y de su momento histórico. Esto quiere decir que el estrés no es solo un malestar físico, sino también social y político, que va más allá del cuerpo y del ámbito laboral. Desde estos soportes teóricos apunté que las operadoras razonan

8 En psicología organizacional, medicina legal y antropología médica, se sabe que la definición de enfermedades profesionales tiende más a monetarizar el riesgo, es decir, a definir una pensión en términos monetarios, que a visibilizar los problemas estructurales que los generan. Debo aclarar que la lucha por el reconocimiento del estrés como enfermedad profesional, sin hacer una indagación profunda que incluya las causas y los procesos, da pie a una configuración etiológica de la enfermedad, a su consecuente medicalización y a la monetarización del riesgo. 
y reflexionan acerca de sus estados físicos o emocionales principalmente a partir de la experiencia del padecer y de su cuerpo, pero son las relaciones sociales, culturales e ideológicas en las cuales se encuentran inmersas las que proveen la lógica de tal racionalidad (Ramírez 2010, 50).

Con la orientación de la relación actor/contexto, una de las hipótesis propuestas destacó que los diversos significados del estrés que se crean en una compleja concepción construida desde la experiencia corporal, en relación con diversos contextos y en diferentes momentos históricos, se despliegan en sucesivas metáforas que posibilitan articular ámbitos aparentemente separados, como el laboral y el familiar. En este sentido, para comprender el estrés fue preciso tener en cuenta no solo lo que las operadoras significaban sobre este o aquello a lo que consideraban estresores, sino también la manera como lo afrontaban o actuaban para dominarlo, tolerarlo o reducirlo. Con ello advertí la importancia de visibilizar los factores o componentes que se precisan para su comprensión.

En síntesis, desde mi perspectiva, el estrés es un malestar físico, emocional, social y moral, cuyos orígenes y consecuencias son estructurales y están referidas a las relaciones sociales y al individuo. Visto como proceso, considero que su expresión varía a lo largo de la vida y depende de lo que para cada persona sea un estresor o circunstancia adversa, que pone en riesgo o en mayor probabilidad de enfermar, y de la manera en que esta considera que dispone de determinados recursos de resistencia - individuales y sociales - para dominarlo, tolerarlo o reducirlo (Ramírez 2010, 45).

A partir de estas elaboraciones teóricas, cuyo propósito fue construir el estrés como objeto de estudio antropológico, generé un modelo analítico alternativo a la corriente hegemónica que estudia el estrés desde metodologías cuantitativas. Dicho modelo pugna por una perspectiva relacional entre actor y contexto, y además entre los diferentes contextos significantes (trabajo y familia) en los que se desenvuelven los conjuntos de trabajadores, suponiendo que sus múltiples pertenencias sociales matizan la expresión de la relación estrés/ trabajo, modelan las prácticas de atención corporal o de salud y enfermedad, y producen una lógica de explicación que articula esas múltiples pertenencias.

Una de las primeras reflexiones de dicha elaboración soportada con datos de campo la desarrollé por primera vez haciendo alusión a un modelo para armar (Ramírez 2005a). Su propósito central era definir los elementos constitutivos del estrés, poniendo particular atención en la construcción de actores sociales y destacando que en un grupo aparentemente homogéneo existen diferencias 
generadas por los múltiples roles que experimentaron las operadoras ${ }^{9}$. A diferencia de aquel, el cometido del presente texto tiene una orientación que pone el acento en lo metodológico, en cómo al explicitar conceptualmente el estrés podemos ir configurando una nueva propuesta en el orden interpretativo, visibilizando los elementos que lo estructuran como proceso, pero además destacando tanto la significación de las operadoras como el ordenamiento teórico, a través de un análisis categorial ${ }^{10}$.

Con lo anterior me interesa destacar la importancia de una antropología reflexiva que articule la teoría y el dato en el ejercicio crítico de la investigación. Una antropología reflexiva pone atención a la jerarquía epistemológica de los actos científicos en la que, como lo han mencionado Bourdieu y colaboradores (1975), la comprobación queda subordinada a la construcción y esta, a la ruptura. Por ruptura entiendo la distancia necesaria que se crea al convertir las nociones de sentido común en nociones científicas tras una permanente actividad reflexiva y crítica lógica. Desde este punto de vista, en la investigación del estrés como metáfora privilegié la construcción de un objeto de estudio que puso atención a la relación que guardan ciertos factores individuales y contextuales (de orden biológico, social, cultural e ideológico) para su explicación y comprensión. Así que, antes de aplicar un modelo instituido en el ámbito de la psicología, cualquiera que este sea, orienté mis pasos a través de la definición del estrés y de la configuración de sus posibles elementos explicativos, en términos teóricos y posteriormente a partir del dato empírico, o sea, desde la experiencia de las operadoras telefónicas, estableciendo así un modelo para armar.

\section{Componentes de estrés}

El ejercicio reflexivo se inicia en la propia construcción del problema, suponiendo, en primer lugar, que para la relación actor/contexto se precisaba poner atención a aquello que resultaba de mayor significación para las operadoras y

En Ramírez (2005) se analiza con cierta profundidad quiénes son las operadoras entrevistadas, pero no como individuos sino como sujetos colectivos con capacidad de acción y estructurados a partir de una conciencia de identidad compartida según sus múltiples pertenencias, es decir, sus configuraciones identitarias generadas con base en sus interacciones sociales. densidad etnográfica sino una síntesis reflexiva de ella, que aparecerá en algunos pies de página que remiten al lector a los referentes que sí dan cuenta del dato etnográfico con profundidad. 
convertirlo en categorías orientadoras para el análisis. Compartiendo las inquietudes de autores críticos como Dressler (1996) — quien apuntó que el problema del estrés requiere no solo esclarecer qué es el estrés y su relación con la enfermedad, sino demostrar de manera refinada y sistemática el proceso que involucró-, me propuse develar los factores relevantes en su aparición, determinando la interacción entre estos y examinando cómo dicha interacción se modifica según los contextos sociales y culturales en los que ocurren.

Teóricamente, el modelo de estrés que tiene su origen en la propuesta de Selye (1976) destaca que existen factores internos y externos que agotan o exceden los recursos del individuo, y se expresan como una respuesta neurohormonal orquestada como defensa corporal ante tales factores considerados nocivos o estresores. Sin embargo, aunque ha habido mayor claridad en la comprensión de los factores de riesgo o estresores al tener en cuenta tanto los internos como los externos, la gran tendencia (biopsicosocial) de los modelos analíticos sobre estrés ha dejado de lado la comprensión de los factores internos, que provienen de la valoración o significación que los actores hacen de sus circunstancias, y se han centrado más en los factores externos considerados estresores (Ramírez 2014a). Pero la pregunta ¿por qué no todos los trabajadores expuestos a los mismos factores de riesgo o estresores se enferman de estrés? siguió abriendo la posibilidad de pensar en las formas de valoración o interpretación con las que cuentan para afrontarlo, dependiendo de otros recursos (económicos, culturales, ideológicos) a los que infortunadamente se accede de manera diferencial. Así, los estudiosos de estrés (Pearlin 2010; Pearlin y McKean 1996) advirtieron que existen estresores 0 factores que desencadenan o producen reacciones físicas, emocionales y sociales en los individuos, y recursos de afrontamiento y apoyo social, considerados factores que cumplen la función de amortiguar, moderar, tolerar y en consecuencia poder responder a aquellos. Los estresores pueden ser agudos —eventos vitales que refieren a crisis o transiciones en el ciclo de vida - o crónicos — aquellos que no violentan de manera momentánea, como lo hacen los eventos vitales, sino que persisten en la estructura de los roles sociales cotidianos y sus circunstancias-.

Para estos estudiosos, los recursos de afrontamiento tienen la función de amortiguar o moderar el estrés en un orden personal, ya que aluden a los esfuerzos cognoscitivos y conductuales que los sujetos implementan ante lo que perciben como estrés o estresores, mientras que el apoyo social, que se refiere a la disponibilidad de ayuda real o imaginaria con la que cuentan los sujetos en momentos de necesidad, es del orden social. Aquí se estima la importancia de la interacción social que el sujeto logra con los otros para generar una red o sistemas de apoyo en el orden socioemocional, instrumental e informativo. 
A partir de estas orientaciones conceptuales - estresores, recursos de afrontamiento y moderadores-, me di a la tarea de crear mis propias categorías con el propósito de que fueran acordes con la perspectiva interpretativa y relacional del estrés. Con ello busco evitar una utilización acrítica de los conceptos que provienen del área de la psicología, pero también, como lo ha mencionado Pearlin (2010), para contribuir a una reflexión refinada de la investigación que atiende a la revisión y el uso de conceptos.

\section{Un modelo para armar desde la construcción del dato antropológico de estrés}

Como lo he señalado en otros textos (Ramírez 2007a, 2010, 2011b, 2014b), el recurso metodológico adecuado para abordar el significado social ha sido el trabajo etnográfico desarrollado por cerca de un año dentro del centro laboral más antiguo de la empresa Telmex. El trabajo se concentró en un grupo de veinticinco operadoras a quienes entrevisté en sucesivas ocasiones a fin de tratar con cierta profundidad los temas apuntados como categorías orientadoras ${ }^{11}$. Me enfoqué en la narrativa para entender la lógica expresada en la forma en que ellas experimentaban y evocaban su padecimiento vinculado a su historia laboral y familiar y, además, la manera en que emergían diferentes circunstancias, momentos, situaciones, personas, así como su propia persona, haciendo uso de su ir y venir en el tiempo y advirtiendo las diferentes transformaciones que operaban en diversas esferas de su vida. El paradigma en el cual se sustenta esta propuesta ha sido el del punto de vista del actor (Geertz 1984) como metodología idónea para dar cuenta de ese mundo significante ${ }^{12}$. El punto nodal de esta propuesta

11 La investigación se enfocó en el ámbito laboral, pero se extendió hasta los hogares de las participantes con la intención de comprender las relaciones en tensión y las múltiples demandas generadas por los diversos roles sociales. Así, dio cuenta de la manera en que tales contextos influyeron en la aparición de estrés en diversas modalidades y de manera muy compleja. Además, analicé con detalle el puesto de trabajo de la operadora con sus características y exigencias antes y después del cambio tecnológico, y encontré múltiples y complejos factores laborales y extralaborales comprendidos en la explicación de estrés. Al analizar la información procedente de ambos dominios, advertí la importancia de armar un modelo interpretativo de estrés.

12 En antropología, la referencia obligada es Geertz (1984), quien habla del punto de vista del nativo, noción que ha sido ampliada con la de actor social, que reconoce que los sujetos con los que hacemos investigaciones, para la comprensión de todo fenómeno social, son sujetos colectivos 
pretendió resolver un problema con estatuto epistemológico que se refiere a la explicación de cómo los sujetos comprenden y explican, desde su propia perspectiva, la imagen que tienen de sí mismos, lo que piensan y hacen respecto de la realidad sociocultural que experimentan y cómo esto, a su vez, es comprendido y explicado o traducido e interpretado por el antropólogo. Recuperar la voz de los actores implica una propuesta teórica, epistemológica y metodológica orientada a demostrar el proceso de elaboración social del estrés que ilustra el tejido de significados que une la experiencia de enfermedad de los actores con su vida, porque el padecimiento o la enfermedad tienen un desarrollo que involucra no solo al cuerpo o a un segmento de este sino a todo el ser, lo que sitúa su existencia en el orden del significado y la comprensión humana.

Partiendo de la idea de que el estrés se comprende mejor si se elabora su historia desde el momento en que las operadoras se asumen como un $-\mathrm{y}$ con un-cuerpo estresado que le da sentido a esa experiencia y es capaz de reflexionar sobre sus síntomas, orígenes, causas, significados, denominaciones, manejos y todo aquello relacionado con contextos específicos, organicé la producción significativa de sus narrativas a partir de las siguientes categorías: edad, lugar de origen, religión, escolaridad, estado civil, paridad, composición familiar, condiciones de la vivienda, conformación del gasto familiar, apoyo en la familia, historia laboral antes de ingresar a la empresa, carrera laboral como operadora, antigüedad, tipo de trabajo, turnos, jornada laboral, salario, prestaciones, asistencia médica, participación sindical y apoyo social en el trabajo. Todas estas categorías, que conforman el estado socioeconómico y demográfico del grupo de estudio, así como su experiencia laboral, se desagregaron para orientar la indagación sobre los significados y valores de esos mismos eventos y mantener una línea comprensiva del mundo significante de las operadoras, cuyo eje de reflexión fue el estrés en relación con los ámbitos individual, familiar y laboral.

Dado que el problema del estrés es complejo por su naturaleza multivariada y polisémica, esta aproximación fundada en una propuesta relacional, no solo entre actores y contexto sino también entre factores, pretendió identificar, priorizar y articular aquellos factores o categorías que resultaron más significativos para las operadoras. En esta articulación propuse un esquema de explicación causal de estrés, que surgió también de manera relacional entre mi elaboración teórica y el dato empírico proveniente de la propia experiencia de las operadoras.

con capacidad de acción y estructurados a partir de una conciencia de identidad compartida según sus múltiples pertenencias, o sea, sus configuraciones identitarias generadas por sus múltiples roles sociales. 
Finalmente, la imbricación de los dos procesos fue orientada por los datos producidos en campo, a partir de lo cual observé que las categorías que se ponen en juego fuertemente para la explicación son, en orden de importancia: antigüedad laboral, tipo de trabajo (tareas, tiempos, funciones, jornada, turnos, trabajo extra), estado civil, presencia de los hijos, participación sindical, apoyo social que perciben - ya sea en el trabajo o en la familia—, escolaridad y, por último, edad.

Cada una de estas categorías ha sido observada como un proceso que muestra una intención a partir de cómo lo viven las operadoras, es decir, pueden verse como agentes provocadores de estrés, como elementos que apoyan para resistirlo o bien como mediadores, cuya función también fue mitigar o potencializar la problemática del estrés.

Desde esta perspectiva, para efectos de la descripción y el análisis, y apoyada en las diferentes investigaciones que han abordado el estrés articulando diversas variables, propongo que las categorías antigüedad laboral, tipo de trabajo, estado civil y paridad tuvieron alta significación para el grupo, mostrando problemáticas y conflictos que eventualmente excedían sus capacidades, así que las configuré potencialmente como estresores, ya que confirmaron lo que teórica y empíricamente han destacado varios autores al abordarlos como estresores crónicos. Debo subrayar que tales categorías no se examinaron como entidades estáticas o referencias numéricas sino como significaciones cuya importancia se hizo más evidente al estudiarlas desde la constitución de roles sociales o pautas de conducta que impone la sociedad (ser esposa, madre, cuidadora del hogar, trabajadora, sindicalista, etc.) y que refieren al mundo familiar y al mundo laboral, dado que supuse que, en el encuentro de ambos mundos, el estrés podría hacer implosión ante la excesiva carga de los roles ${ }^{13}$. Me interesó atender a los roles sociales ya que la clave distintiva de la antropología es justamente estudiar las relaciones sociales y los roles, entendidos como creaciones sociales, que son los que configuran las relaciones que se dan entre actor e instituciones como el trabajo y la familia, las cuales poseen unas normas implícitas que pautan el comportamiento social.

A fin de subrayar lo propiamente antropológico del trabajo, esas categorías fueron tratadas como experiencias de vida estresantes, dado que lo que me

13 Considerando la importancia de los roles sociales, algunos autores como Brown y Harris (1978) pusieron tempranamente atención a la relación trabajo - roles sociales - enfermedad, explorada con diferentes propósitos pero demostrando la importancia del significado social. En el mismo sentido, Pearlin $(1983,2010)$ investigó los roles sociales centrándose en determinadas obligaciones de rol, expectativas, percepción de cautividad, si se viven como ganancias, pérdidas, insatisfacciones o si pueden implementar negociaciones para ejercer múltiples roles con mayor éxito. Particularmente, en la relación trabajo-familia Wheaton (1990) resalta que el estrés puede expresarse justo en ese encuentro. 
interesaba era justamente mostrar el estrés como proceso y no como fenómeno estático, cuestión que logré visibilizar gracias a la narrativa vigorosa de cada una de las participantes, pudiendo develar así la fuerza cultural de las emociones a partir de lo local ${ }^{14}$.

Al indagar sobre lo que las operadoras pensaban sobre el estrés, pero también sobre cómo respondían a este, advertí que algunas estaban familiarizadas con la noción de manejo de estrés, dado que la compañía había dado varios cursos para empezar a atender el problema. El manejo refirió al modo en que las operadoras resolvían o se sobreponían a las experiencias estresantes, o bien, a las acciones o prácticas que ellas pusieron en juego cotidianamente para reducir el impacto de tales experiencias. Justamente en sus relatos pude distinguir algunas respuestas pasivas o activas respecto de las valoraciones que hicieron sobre su situación. De esta manera apareció la participación sindical como un rol social de trascendencia, no solo por brindar información sobre las condiciones de trabajo y salud del gremio sino también por configurar un espacio de recreación colectiva. La participación sindical develó su importancia en un doble orden, porque generó un sentido de pertenencia al conformarse como la plataforma básica para la constitución de las operadoras como "sujeto político", y porque brindó una cobertura ideológica cultural que las proveyó de creencias sobre la protección, el apoyo mutuo y el sentido de seguridad social.

Siguiendo la línea del apoyo social, indagué sobre las formas de relación, en el trabajo y la familia, configuradas como redes sociales de apoyo, pues es sabido que la pertenencia a tales redes, o bien saberse apoyada en el trabajo -ya sea por las supervisoras o por las compañeras-y en la familia - por la pareja, familiares y amigos-, contribuyó fuertemente a mitigar los problemas de estrés. Así, la participación sindical y el apoyo social percibido fueron configurados bajo la rúbrica de recursos de resistencia, ya que estos se trazan específicamente para contestar y actuar ante el desafío, es decir, responden a motivos que generan interacciones y respuestas elaboradas por las participantes en una situación de conflicto o exigencia dada. Por último, consideré escolaridad y edad como categorías que caracterizan a una población y también como categorías mediadoras o moderadoras, tal como algunos autores lo han planteado (Baron y Kenny 1986), ya que al relacionarlas con otras, por ejemplo, con las experiencias de vida estresantes, advertí que podían tener la función de mitigar

14 Con esta idea aludo a que cada espacio laboral producía una respuesta emocional en las operadoras, lo que muestra que las emociones no son solo respuestas fisiológicas sino formas de relación que van dando pautas para la comprensión de la conflictividad cotidiana y de la producción de estrés (Ramírez 2007a). 
o potencializar la problemática de estrés. Este ordenamiento categorial queda referido en el siguiente esquema:

Figura 1. Modelo interpretativo de estrés en operadoras telefónicas

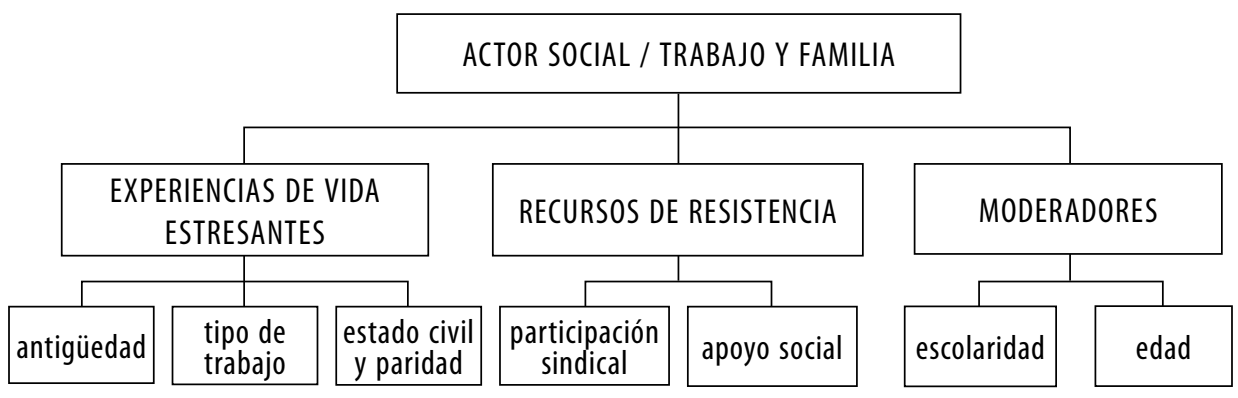

Fuente: elaboración propia a partir de la formulación teórica y un primer ordenamiento y clasificación de la información de campo.

\section{La tarea del análisis cualitativo}

Hasta aquí he venido hablando de la construcción de un modelo analítico de estrés, sin aún mencionar lo que significa la tarea de analizar los datos cualitativos. No obstante, el lector podrá advertir que dicha tarea comienza con la creación de un problema de estudio y continúa al visibilizar con claridad de dónde proviene la información y cómo se obtuvo ${ }^{15}$, para después describir los procedimientos de organización, clasificación y codificación. Ciertamente, este procedimiento no es fácil de describir y por demás excede el propósito del texto. Sin embargo, considero pertinente mencionar que el análisis cualitativo tiene como característica mantener una línea argumental coherente teórica, conceptual, metodológica y empíricamente. Desde este punto de vista, el procedimiento seguido ha sido la contrastación permanente de la teoría y el dato, desde los primeros encuentros en campo. El siguiente paso es una estrategia que parece simple pero resulta compleja a medida que se avanza en el ordenamiento de la información, que pasa de la transcripción de la entrevista a la conformación de un texto convertido en relato, en el que la primera persona que habla es la entre- 
vistada $^{16}$. Estos relatos dan forma a la narrativa de las participantes a través de la cual se presentan los acontecimientos clave, la interacción social y la experiencia, y dan paso a lo que Denzin (1989) ha descrito como interaccionismo interpretativo, es decir, la relación entre los procesos sociales y las vidas personales.

Para el ordenamiento, codificación y clasificación de la información he seguido la propuesta de Huberman y Miles (1994), quienes destacan tres subprocesos ligados entre sí: 1) reducir los datos a través de una codificación y clasificación por temas, grupos y categorías; 2) exponerlos en diagramas o cuadros a fin de mostrar lo que implican; y 3) sacar y verificar conclusiones a través de contrastes y comparaciones, observando y explorando temas, patrones e irregularidades, y poniendo especial énfasis en las metáforas utilizadas por las entrevistadas.

Los dos primeros puntos están contenidos en el modelo propuesto. Sintetizaré algunos de los resultados obtenidos al relacionar las categorías para armar el modelo.

\section{Explicación categorial. Algunos resultados Experiencias de vida estresantes}

\section{La antigüedad laboral}

La antigüedad laboral ha sido importante en numerosos estudios sobre salud ocupacional, psicología industrial, medicina social y salud en el trabajo, por la relevante relación entre enfermedad y tiempo de exposición (Stellman y Daum 1986). Es una categoría que se ha relacionado con distintas variables a fin de entender la satisfacción o insatisfacción en el trabajo y la historia laboral.

Para el presente estudio abordé la antigüedad laboral como trayectoria, para revelar información relativa a las transformaciones que las operadoras sufrían en tanto trabajadoras, en tanto mujeres y en ese tránsito eventual que ocurre en tanto enfermas. Por ello, si bien los años dedicados al empleo son importantes por la relación que puede observarse entre trabajo y enfermedad, también proporcionan información sobre el proceso de constitución del "ser trabajadora”, porque una trayectoria de trabajo va dando pautas de constitución del

16 Esta es una estrategia desarrollada de manera personal que ha sido potenciada por el cuidado y atención que he puesto en el proceso de investigación. Al ser yo quien elabora el diseño de investigación y lo pone en marcha en un trabajo etnográfico in situ, logro un conocimiento agudo que permite el desarrollo de la imaginación y la interpretación. 
sujeto trabajador, de los lineamientos para asumir las funciones, normas, reglas y valores dispuestos en el medio laboral, que conforman un cuerpo disciplinado. Y dado que la salud, la enfermedad y su atención son temas y problemas de experiencia cotidiana, las prácticas y representaciones de estas, y su atención, se perfilan dependiendo de esa trayectoria laboral observada desde el significado social (Brief y Nord 1990).

Además, los años de trabajo analizados como trayectoria y desde el significado (por ejemplo, del trabajo y del ser trabajadora) muestran en síla expresión de los roles sociales a través de las necesidades, los logros, los estancamientos, los sentimientos de frustración, las expectativas de cambio, los satisfactores e insatisfactores y sirvieron para esclarecer la manera en que las operadoras respondieron a dos eventos importantes: tiempo de exposición, a lo que algunos investigadores llaman estrés de rol (Peiró et al. 1992), y cambio tecnológico, analizado como factor que genera riesgo de estrés por cambios en el proceso productivo (Balka 1995) ${ }^{17}$. Analizar estos dos eventos resultó relevante porque tales transformaciones reorientaron el significado que las trabajadoras le adjudicaron a su propio trabajo, ya fuera en términos positivos o negativos. Por ejemplo, en términos positivos se observó la posibilidad de ver su trabajo como elemento protector, aun cuando se advierte el propio deterioro de la salud ${ }^{18}$. En términos negativos destacó un evento que me pareció revelador del malestar y que ha sido analizado a través de pautas emocionales que dan cuenta de la pérdida de oficio ${ }^{19}$.

\section{Tipo de trabajo}

La manera en que se realiza un trabajo, las funciones, los tiempos y las tareas que lo conforman han sido abordados desde muy diversas perspectivas como po-

17 La narrativa que muestra los efectos del cambio tecnológico fue analizada al comprender cómo las transformaciones del mundo laboral conducidas por una ideología productivista se inscriben en el cuerpo de las operadoras a través de una ideología que utiliza el poder, el control y la disciplina mediante una vigilancia excesiva que se incorpora, es decir, se hace cuerpo en las operadoras hasta volverse una rutina que parece orientarse por ellas mismas y cuyo resultado fue la transformación de cada operadora en vigilante de las otras. Al mismo tiempo, todo ello dio pie a pequeñas respuestas de resistencia que, matizadas por la ansiedad gestada cotidianamente, fueron expresadas como coraje al ser insultadas por el cliente o ser tratadas como máquinas por la empresa, la cual, en busca de la calidad y satisfacción del cliente, les impide mostrar emociones que no sean favorables a esta. Véase Ramírez (2014). salud provee de un espacio de recreación para la operadora; véase Ramírez (2007b).

19 Al analizar la trayectoria laboral, un elemento relevante y recurrente en la narrativa de las operadoras, resaltó la pérdida de los contenidos simbólicos del trabajo. Para ampliar, véase Ramírez (2011b). 
sible fuente significativa de estrés, en especial si todo ello deriva en una mayor demanda de cantidad de trabajo que se relaciona con bajo control por parte del trabajador y excede sus capacidades (Karasek 1998). Existen numerosos modelos que tienen en cuenta estas categorías; sin embargo, el modo en que se conforma la jornada laboral en el caso de las mujeres, atendiendo a las especificidades de cada tipo de trabajo, la rotación de turnos, el trabajo nocturno y la prolongación de la jornada, ha recibido poca atención ${ }^{20}$.

Entre las participantes, tanto la rotación de turnos como la posibilidad de extensión de la jornada al doblarlos se enfrentan de manera compleja, toda vez que se asumió como una cuestión benéfica en términos monetarios, que en la práctica opacó los efectos sobre la salud. Así que, aunque ellas no ponderaron su trascendencia en este sentido, la información derivada de su experiencia de estrés mostró que algunos síntomas como cansancio, insomnio, hipersomnia, alteraciones de la memoria y falta de concentración estuvieron claramente asociados a esa forma de trabajar ${ }^{21}$.

Por otra parte, aunque el mundo de la telefonía en los últimos cincuenta años mejoró paulatinamente, el proceso de cambio tecnológico generado en el tránsito del conmutador analógico al sistema digital (en la década de los noventa) marcó las vidas laborales de las operadoras, quienes utilizaron la noción de "un antes y un después" en un proceso de remembranza de todo lo que tiene que ver con el oficio. Esto fue perfilando tanto la constitución del ser trabajadora y sindicalista como su declive. Ubicadas en el después, todas las participantes refirieron con nostalgia cómo era el trabajo antes. Aunque reconocieron que hubo mejoras, también afirmaron que hubo pérdidas ${ }^{22}$. Desde su punto de vista, las mejoras en el puesto de trabajo que prometió la empresa con la transformación tecnológica se desdibujaron ante el golpe tremendo que representó el nuevo perfil de la operadora, que parecía exigirles que se comportaran como máquinas ${ }^{23}$. Esto fue descrito

Las operadoras son de los pocos conjuntos de trabajadoras que pueden extender su jornada en función de sus necesidades monetarias, doblando turnos a través de acuerdos de carácter personal entre pares sin intervención de la empresa.

21 Cuando hablé de las causas que estaba encontrando para la explicación del estrés ante el grupo de operadoras, algunas expresaron: "no se te ocurra mencionar que el 'trabajo por' [es decir, trabajar por alguien que no puede por razones personales, y con ello mantener un trato de mutuo beneficio] tiene que ver con el estrés", pero la información generada por ellas mismas fue contundente.

La nueva tecnología implementó una disciplina corporal diferente, de atención intensiva, movimientos repetitivos, constreñimientos posturales, aunque también dio paso a la posibilidad de pausas más frecuentes durante el trabajo. boral con el lema "el cliente es lo primero". Esto se tradujo en nuevas y mayores exigencias 
por ellas como un proceso de "deshumanización de su trabajo", acompañado por la desvalorización de este, la pérdida de las redes sociales de apoyo y el aumento de la competitividad generado por el programa de productividad.

En todo lo concerniente al tipo de trabajo, la narrativa de las operadoras fue abundante y cargada de profunda emotividad, de modo que pudo mostrar no solo las transformaciones generadas en sus roles sociales sino también en sus relaciones, en su contexto, en su cuerpo y en su yo. Transformaciones que desnudaron un ambiente hostil, exigente e incluso violento (Ramírez 2011b), que afectó las relaciones interpersonales provocando enojo, frustración y ansiedad ${ }^{24}$. Pero también y ante ello pude constatar pequeñas y grandes respuestas de resistencia mostradas a través de procesos metafóricos ${ }^{25}$.

\section{Estado civil y paridad}

Partiendo de la noción durkhemiana de que determinadas configuraciones de roles sociales pueden proteger o generar vulnerabilidad a la enfermedad y a la muerte (Durkheim [1897] 1976), concebí la importancia de incluir las categorías estado civil y paridad, ya que remiten a roles que los sujetos experimentan cotidianamente.

A lo largo de cuatro décadas, los estudios que tratan la expresión de los roles sociales, tanto en el trabajo como en la familia, se han modificado, pues algunas propuestas iniciales (Nathanson 1989) subrayaron que el rol de trabajadora era benéfico para la salud per se, e incluso mostraron con datos cuantitativos que las mujeres trabajadoras que ejercían varios roles sociales eran más saludables que las que realizaban pocos (Froberg et al. 1986). La investigación que se ha desarrollado en el presente milenio ha expuesto reflexiones relevantes que parecieron aceptar la explicación del estrés desde la noción figura-fondo, propuesta por Lazarus (1999), al afirmar que el estrés interactúa en ambos dominios, siendo la familia el fondo para el estrés laboral y el trabajo, el fondo para el estrés familiar. En este sentido, ha habido gran interés en explicar el estrés relacionando

hacia las operadoras y en un control ideológico que las hizo aparecer culpables de su propia "extinción" si el cliente no quedaba satisfecho o si no era recuperado como usuario.

Los efectos del cambio tecnológico fueron muy complejos y es imposible sintetizarlos aquí; por ello, remito a Ramírez (2010b), texto en el que, a través de dos capítulos etnográficos, se detalla con profundidad el proceso de estrés desde la metaforización mostrando el lado deshumanizante de la tecnología y la aparición del estrés con manifestaciones emocionales de diversa índole.

Leer a escondidas durante el trabajo o escribir papelitos a las amigas, así como llorar para manifestar que el cliente les dice obscenidades, son metáforas de resistencia ante la exigencia de comportarse como máquinas. Véase Ramírez (2010b). 
los roles derivados del ámbito laboral y el familiar y utilizando, en el mundo anglosajón, la noción de spillover ${ }^{26}$. Con este concepto los investigadores han dado cuenta de la manera en que el mundo laboral y el familiar se encuentran y pueden generar la sensación de estar "desbordado".

En mi investigación, la evidencia etnográfica mostró que sentirse desbordada ocurrió en el ejercicio de diferentes roles como esposa, madre, amante, jefe de familia, cuidadora de los otros y trabajadora, y se expresaba en situaciones que las operadoras vivieron y experimentaron, dependiendo de las exigencias que percibieron en tales roles, de la presencia o ausencia de una pareja, de la presencia de los hijos y sus demandas, de la exigencia social de que sea la madre la cuidadora de estos y del apoyo social brindado tanto en el trabajo como en la familia. Sus referencias, que aludieron a la figura-fondo de Lazarus, utilizaron la noción de estallido que se expresó en la familia al llevar las tribulaciones del trabajo al hogar y, en consecuencia, gritarles a los hijos o al marido. Pero el estallido también aludió al momento en el que las angustias y exigencias de la familia se trajeron al trabajo, y se gritó y se manifestó enojo, irritación e incluso violencia, pero que tuvieron que ser acalladas o falseadas debido al constreñimiento del mundo neoliberal que supone y exige que todo lo que no concierne al trabajo se quede fuera de este (Ramírez 2010).

El estado civil permitió indagar por las expectativas de las operadoras depositadas en el ser esposas, en sus ideas sobre la familia o en su predilección por la soltería. Esta categoría me dirigió de manera inmediata a abordar los valores de la maternidad, la paridad, la edad, así como el intervalo intergenésico, que pautan sus necesidades afectivas, sociales y políticas y orientan sus decisiones con respecto a cambiar su estado civil. A partir de sus relatos, advertí que en todos esos procesos se generaron constantemente valores y significados que estuvieron relacionados con satisfacción e insatisfacción, así como con estados emocionales adversos dependiendo de la edad y de la antigüedad laboral. De manera tal que tanto el estado civil como la paridad fueron procesos que, articulados a la vida laboral, es decir, a su "ser trabajadora", tuvieron un peso importante en la explicación de la ocurrencia de diversos padecimientos y de la configuración del estrés.

La expresión work-family spillover, de difícil traducción, ha sido utilizada para referir los efectos que tiene el trabajo en la interacción familiar. La investigación inicial surgió para indagar si el empleo de madres trabajadoras podría afectar negativamente a sus hijos y familiares. Sin embargo, esta suposición pintó un cuadro demasiado simplista de la vida laboral y familiar, ya que la amplia investigación de las últimas dos décadas, realizada básicamente por mujeres a nivel internacional (Kossek y Lambert 2005; Perry-Jenkins, Rena y Crouter 2000; Repetti y Saxbe 2009), muestra que las características específicas de los puestos de trabajo y sus experiencias, más que el trabajo en sí mismo, tienen consecuencias tanto positivas como negativas para la familia. 
Para finalizar este apartado quiero señalar que la experiencia y el significado creados socioculturalmente, ya fuera en el trabajo o en la familia, referidos a través de las múltiples pertenencias de las operadoras, mostraron efectivamente que, en términos generales, las exigencias extremas en el ejercicio de los roles sociales se advirtieron como experiencias de vida estresantes, que tuvieron diversas expresiones dependiendo del apoyo social y de sus capitales culturales, sociales y políticos para resolver con mejor fortuna las desavenencias.

\section{Recursos de resistencia}

\section{Participación sindical}

Se sabe que los sindicatos son instituciones de clase, que se conforman a partir de un juego de normas y valores que definen el rango de prácticas y tipo de interacciones permisibles dentro de un conjunto social caracterizado por su trabajo. También se sabe que estas instituciones se han transformado a partir de procesos económico-ideológicos complejos - democratización de las estructuras sindicales, reconversión, privatización, nueva tecnología, productividad, movimiento feminista-, que han reformulado dichas prácticas e interacciones. No obstante, poco se sabe de la posible relación existente entre las problemáticas de salud y su expresión a través de la vía sindical —me refiero a estudios realizados de manera conjunta— ${ }^{27}$.

Pero las investigaciones sobre el tema son escasas, aunque se destaca de manera notable un estudio que me orientó para comprender el sindicato, o la participación sindical, desde su papel potencial para la reducción de estrés, no solo por la información y las acciones que se puedan lograr a partir de ello, sino por la apreciación de lo que significa tener un sindicato preocupado por mejorar las condiciones laborales y de salud (Lowe y Northcott 1993). Estos autores señalan, por ejemplo, que el estrés laboral será más llevadero si existe una idea de sindicato que se muestre eficaz ante dichas problemáticas y, por el contrario, se percibirá en aumento si hay una apreciación de desprotección y abandono por parte del sindicato.

Si bien este hecho resultó trascendente entre las operadoras como gremio, no fue un aspecto que hubiera tenido en cuenta de manera inicial en la

27 En México hay algunas referencias interesantes que aluden a la importante participación que en la década de los ochenta realizamos algunos investigadores de la UAM-X y de la ENAH para, a través de los sindicatos, manifestar y crear conciencia sobre la salud. Quizá las operadoras telefónicas fueron un actor social de gran relevancia por su práctica política derivada de su situación estratégica en la telefonía. 
investigación, aunque los datos empíricos me condujeron a volver la mirada a la práctica sindical como un elemento importante en la configuración del estrés.

Cuando inicié la averiguación sobre qué sabían las telefonistas acerca del estrés y qué hacían al respecto, lo hice pensando en atender a las formas que utilizaban para resistir a sus embates. Me sorprendió encontrar mujeres activas y muy informadas sobre sus circunstancias, y esto sin duda se debió a su constitución como sujeto político configurado a través de su participación sindical. De modo que lo que hacían para mitigar el estrés estaba definido por una expresión colectiva que pudo, en determinado momento, hacer que el sindicato volviera los ojos hacia ellas y les otorgara ciertas atenciones para contener o resolver el estrés ${ }^{28}$.

La narrativa vigorosa y detallada de las participantes mostró su "ser trabajadora” como el eje que estructuró su relato; pero al mismo tiempo que mencionaban que "eran más felices" antes del cambio tecnológico porque se sentían más integradas, sus reflexiones hicieron emerger constantemente su ser político. Aparecieron el sindicato y la participación sindical como un espacio de cobertura ideológica y soporte cultural ya que, por lo menos en algún momento de su historia laboral, el sindicato se percibió como un sitio que proveía identidad y fue el medio más eficaz a través del cual las operadoras ejercieron sus derechos de salud y de legislación sobre seguridad laboral. Aunque esto fue, desde mi perspectiva, más teórico que práctico, para las operadoras el saberse apoyadas por un sindicato generó la posibilidad de pensar su participación y el significado positivo de este como un recurso de resistencia ${ }^{29}$.

La participación sindical tuvo una importancia crucial para este sector porque, ligada a la antigüedad, proporcionó información para entender cómo se construye el "ser telefonista", es decir, el oficio de manera muy articulada con el

28 En casi todos los centros laborales, afuera de las salas de trabajo podía encontrarse una sala de gimnasio para que las operadoras hicieran ejercicio. También se llevaron a cabo cursos sobre manejo de estrés, pero solo a un grupo selecto que después compartía la información con el resto de sus compañeras. En este sentido, el activismo sindical sí estuvo tratando el problema del estrés y la comunidad de alguna manera participaba de ello, y se consideraron así ciertas acciones para afrontarlo.

En los primeros años del presente milenio apenas eran conocidos los trabajadores de call centers. De hecho, algunas de las operadoras comentaron que la propia empresa subcontrataba con pequeñas empresas que empleaban a jóvenes para ese tipo de trabajo. De modo que conocer sus condiciones laborales sin sindicato las hacía pensar inmediatamente en el sentido protector de este, aun cuando se reconocía a su líder sindical como "neocharro", es decir, un dirigente que, aun criticando al charrismo sindical por las prácticas de control político ideológico de los trabajadores para beneficio de los patrones, no logró desterrarlas del todo; prueba de ello es que tiene cerca de cuarenta años dirigiendo el sindicato de telefonistas. 
“ser sindicalista”. En otras palabras, su representación como "sujeto político”. La participación sindical considerada como recurso de resistencia les brindó apoyo, información y la capacidad de reflexionar sobre sus circunstancias y negociarlas, en un sentido más notable que el propio nivel educativo ${ }^{30}$.

\section{Apoyo social}

El apoyo social se refleja en el ámbito de las relaciones sociales que importan porque constituyen redes de apoyo social que las personas generan, bien en su trabajo o en la familia. Teniendo en cuenta la idea de que los trabajadores que se sienten apoyados en sus familias y por sus jefes manifiestan menos estrés (Frankenhaeuser 1989) y que el apoyo social —sobre todo para los niveles profesionales más bajos - reduce la ambigüedad de rol, la carga excesiva y la incertidumbre en el trabajo (Marcelissen et al. 1988), así como la relevancia en las diferentes dimensiones existentes (House y Kahn 1985), indagamos por el apoyo social en tres órdenes: el ámbito laboral, el familiar y el individual.

Relacionar las categorías que he apuntado hasta aquí ofrece un juego muy complejo de posibilidades. Pero en un intento de síntesis puedo decir que una de las cuestiones más significativas en las narrativas de las operadoras fue que el cambio social experimentado por la innovación tecnológica, aparte de generar experiencias estresantes, alteró la naturaleza de los sistemas de apoyo sociales tradicionales que se mantenían, sobre todo entre pares. Se habló de una sensación de ruptura en dichas relaciones por las nuevas posiciones ergonómicas que no permitían la comunicación entre operadoras; se subrayó que la disciplina y el control laboral acentuaron las diferencias entre operadoras y supervisoras, lo que generó relaciones hostiles y un clima de competencia, envidia y animadversión activado por el programa de productividad. Como resultado, el apoyo social en el trabajo, entendido como solidaridad, compañerismo, comprensión, acompañamiento, instrucción y respaldo, estuvo matizado por la situación que enfrentaban las operadoras a inicios del 2000.

El apoyo social fue caracterizado por las operadoras de dos formas: entre compañeras, aunque este también es fragmentado por las razones expuestas, y

30 Así que la experiencia sindical — ser delegada, estar en una comisión- y la vivencia de un momento en el que hay convicción de poder, cohesión y solidaridad - que las operadoras refirieron sobre todo antes del cambio tecnológico y la privatización- proveyeron de más elementos para la reflexión y el manejo. 
entre jefa y subalterna, condicionado a la manifestación de un comportamiento de "buena trabajadora" ${ }^{31}$ y por la afinidad dada por la participación sindical ${ }^{32}$.

\section{Moderadores}

\section{La escolaridad y la edad}

Algunos estudios han considerado la escolaridad y la edad como variables independientes al indagar por correlaciones con la presencia de enfermedades o de estrés (Cedillo y Karasek 2001). En ocasiones, en la búsqueda de asociaciones entre género y estrés se ha observado la importancia de la variable nivel de estudios en relación con la sintomatología depresiva o con un mayor malestar emocional en mujeres profesionales, cuando sus maridos se oponen a que trabajen (Lara et al. 1993). En nuestra propuesta, dichas variables fueron importantes, aunque no de manera central, por lo cual las hemos considerado moderadoras de los agentes provocadores de estrés o de la experiencia de estrés, a la manera en que algunos autores han analizado la relación entre el apoyo social y los estilos de manejo como moderadores y mediadores (Baron y Kenny 1986) para explicar la relación entre el estrés y resultados psicológicos como la depresión (Folkman y Lazarus 1986).

Para el presente estudio la escolaridad del grupo se mantuvo en un nivel medio, ya que en su mayoría tenían estudios comerciales y de preparatoria. Se advirtió que esta categoría no fue influyente en sus circunstancias de estrés, aunque podía ser considerada moderadora al relacionarse a otras categorías, como la participación sindical, y así potenciar sus respuestas ante las adversidades. De esta manera, pude ver que, a menor escolaridad y menor participación sindical, se expresó una menor posibilidad de manejo de situaciones estresantes y viceversa.

Pearlin (2010) muestra que el impacto de los estresores puede variar en el curso de la vida, es decir, a diferentes edades. Según este autor, el estrés crónico

31 La buena trabajadora es aquella "cumplida, que no llega tarde, no falta, no genera conflictos, no pide permisos, deja su vida y sus problemas fuera de su trabajo". Esta es la caracterización reproducida desde ambos lados, que arranca la crítica de las operadoras, pues muestra la inflexibilidad de las supervisoras y un autoritarismo ejercido, según ellas, a discreción.

32 Aquellas operadoras que generalmente tienen enfrentamientos con las supervisoras no se conciben apoyadas en su labor cotidiana y fueron la mayoría $(\mathrm{n}=18)$. Aquellas que perciben apoyo en el trabajo $(n=7)$ son las que en varias ocasiones han desempeñado el papel de delegadas o comisionadas, lo cual permite otro tipo de relación que puede dar elementos para la comprensión y negociación de sus circunstancias, lo que probablemente esté más asociado a un mejor manejo de sus reacciones emocionales negativas. Por el contrario, aquellas que no percibieron apoyo y además sintieron una degradación permanente, por no cumplir con los tiempos, las metas y con el cliente, respondieron a menudo con enfrentamientos en términos irascibles y violentos o se aislaron. Véase Ramírez (2011b). 
es más común en los ancianos, mientras la población joven se enfrenta al estrés agudo. Tuve en cuenta estos señalamientos para ver cómo se expresaba la edad entre las operadoras, pero dado que en el grupo no hubo una diferencia significativa, pues mayoritariamente estaba formado por mujeres maduras cuya media de edad fue 41 años, con un rango de edad de 32 a 54 años, puse más atención a otras variables. Además, quería quitarle el peso naturalizado y psicologizado que a menudo se le da al estrés cuando está asociado a la edad y al género ${ }^{33}$.

Del juego de relaciones de todas las categorías enunciadas (antigüedad, tipo de trabajo, estado civil, participación sindical, apoyo social, escolaridad y edad) resultaron diferentes posibilidades de expresión de estrés. Lo más importante es que, a partir de las narrativas de las mujeres, se demuestra que el estrés es un proceso, por lo que el modelo presentado no puede ser tomado como una organización general estable, sino precisamente como una situación en movimiento que marcó procesos de cambio de las operadoras. En este sentido, para ejemplificar las relaciones entre categorías, puedo decir que a mayor antigüedad y mayor edad las operadoras enfatizaron su rol de trabajadoras y sindicalistas, y por encima de sus roles familiares, al ser ellas quienes proveían el mayor salario al hogar. Eso les generó gran satisfacción, pero en momentos de exigencias familiares les originó sensaciones de culpa que vivieron como estrés ${ }^{34}$.

A menor antigüedad, menor participación sindical, menor edad y menos posibilidades de comprensión y apoyo en sus familias, hubo sensaciones de no pertenencia y de incomprensión que se expresaron con pocos recursos para el afrontamiento. Esto se reflejó no solo en sintomatología de estrés, como ansiedad o dolores musculares, sino también en formas particulares de manejo en los que destacaron los comportamientos evasivos y el aislamiento.

De acuerdo con mis análisis, en este grupo de mujeres lo estructurante es su trabajo, mientras que los roles sociales familiares (estado civil y paridad) quedaron subordinados a los roles laborales, lo cual no ha sido fácil para ellas

33 Cuando consulté ante el sindicato la posibilidad de realizar la presente investigación, el encargado del comité sindical trató de persuadirme de que las operadoras no sufrían de estrés, porque su puesto de trabajo se había transformado ergonómicamente pensando en su salud, de manera tal que si estaban estresadas debía de ser porque la mayoría eran "menopáusicas" (véase Ramírez [2005b]). Esto fue relevante, ya que la menopausia es un proceso biológico, un hecho con contenidos simbólicos que a menudo se usa en los grupos de pertenencia para marcar la vida reproductiva y productiva de las mujeres, pero también es "etiquetada" como un evento descalificador y las mujeres mayores, como histéricas o estresadas, descontextualizando y restándole importancia a la situación estructural en la que se encuentran. dadora de los otros) se expresó de manera muy compleja; se mostraron mayores elementos para afrontar las dificultades en aquellas mujeres que lograron acuerdos y negociaciones en ambos espacios. 
puesto que exigió profundas negociaciones y transformaciones en las relaciones familiares y en lo que ellas pueden creer de sí mismas.

En relación con el tipo de trabajo considerado rutinario, descalificado, tedioso y sin control por parte de la operadora -idea que todas comparten-, encontré algunas diferencias que tienen que ver con la prolongación de la jornada laboral y con el tipo de tarea exigida, a la cual se le imponen cargas simbólicas ${ }^{35}$, dado que está comprometida la continuidad de su oficio. Aquí la relación que resalta es que, frente a la intensificación de la jornada y a mayor presión ideológica y simbólica ${ }^{36}$, las respuestas físicas, conductuales y emocionales remitieron claramente a sintomatología de estrés; esto es ejemplificado por el acoso cotidiano por toda la ideología y la disciplina que les exige ser máquinas y que, desbordada tal exigencia, afecta considerablemente la comunicación en el trabajo y también las formas de integración familiar. Esto, desde luego, depende a su vez de las posibilidades de reconocer lo que está ocurriendo para poder dar respuestas, manejar, controlar o resolverlo.

\section{Conclusiones}

Como lo mencioné al comienzo, el presente texto deriva de una reflexión en la que di inicio a la propuesta de un modelo interpretativo de estrés haciendo alusión a un modelo para armar (Ramírez 2005a). En esta exposición fui más allá, pues describí en detalle un proceso que me interesaba mostrar, en términos metodológicos, de cómo se puede hacer una investigación antropológica sobre estrés desde la reflexividad. Aquí desarrollé una noción de estrés como proceso y desde la significación, y abordé de manera crítica los usos de modelos analíticos de estrés laboral que han fincado su validez exclusivamente en el dato estadístico, destacando la relación estímulo-respuesta que se focaliza fundamentalmente en los llamados estresores externos, pero sin darles un sitio de importancia a los estresores internos; esto es, a los procesos de valoración que los individuos hacen

Por cargas simbólicas me refiero a la concepción de las operadoras de su oficio como una labor noble en vías de desaparecer y de su entrada al mundo competitivo que genera una nueva relación con el abonado, quien ahora es llamado cliente. En esta nueva situación ellas batallan cotidianamente con la idea de "ser una buena operadora", una máquina que no exprese emociones. Para ampliar, véase Ramírez (2011b).

La presión ideológica y simbólica se genera todos los días de acuerdo con lo apuntado en la nota anterior pero además hostigando a las operadoras al decirles que si no cumplen con la productividad van a desaparecer. 
de sus circunstancias — como diría Lazarus (1999) — o bien a los procesos de significación, como lo abordamos desde la antropología, al reconocer que el sujeto es productor de sentido y significación. Este elemento distintivo, con un carácter epistémico notable, es el que orienta la presente reflexión y permite comprender que los trabajadores como productores de sentido elaboran ideas, explicaciones, significados, metáforas y prácticas sobre su cuerpo, su experiencia, sus circunstancias laborales, lo que devela la importancia del contexto que provee la lógica que les da sentido a tales elaboraciones.

Desde este punto de vista, que expone el proceso de construcción del estrés como objeto de estudio antropológico, surgió la primera gran distinción entre los modelos interesados en "medir el estrés" que desdibujan al sujeto y su contexto y la presente propuesta que subrayó el interés de “interpretar el estrés”, exponiendo una ruta reflexiva que antepone la construcción a la comprobación, en la cual aparece el sujeto significante. En este caso, se trata de las operadoras telefónicas, quienes a partir de su propia voz y experiencia, y desde una cierta densidad etnográfica ${ }^{37}$, fueron describiendo a través de diversos procesos de metaforización cómo el estrés no solo puede comprenderse como una respuesta neurohormonal sino en un contexto que devela la importancia de diversos y complejos factores socioculturales abordados a partir de una perspectiva relacional. Así pues, para fines analíticos, emergió el propósito de configurar un modelo interpretativo de estrés que subrayara la importancia de una construcción entre la teoría y el dato. Esto quiere decir que, desde la realidad experimentada por las operadoras, se corroboró la nueva comprensión teórica del estrés concebido como un proceso que articuló el trabajo y la familia a través de un andamiaje de metáforas, cuya comprensión mayor se logró al analizar los diferentes roles sociales, con sus cargas simbólicas y emocionales, que ellas experimentaron. En el mismo sentido, el análisis categorial de toda la investigación de campo que perfiló a las operadoras en términos sociodemográficos y significativos ejemplificó, en este ejercicio reflexivo, cómo los elementos que conforman el modelo interpretativo de estrés no son entidades estáticas o referencias numéricas sino significaciones que tienen presencia en el modelo, precisamente por la alta representatividad o importancia que tuvo para ellas y para su comprensión del estrés. Mediante sus relatos también revalidé los componentes del estrés al afirmar que ellas reconocen cuáles son las experiencias de vida estresantes y cómo las afrontan, es decir, cuáles son los recursos de resistencia con los que cuentan y cuáles son los elementos moderadores que pueden contribuir a mitigar y afrontar el estrés. En un juego de

37 La densidad etnográfica fue desarrollada a lo largo de la investigación, pero sintetizada en términos categoriales para este texto. 
posibles relaciones, el modelo interpretativo permite comprender la experiencia del estrés de las operadoras al analizar la fuerza sociocultural emanada de las pautas de conducta generadas a lo largo del tiempo en el ser trabajadora, esposa, madre, cuidadora del hogar, sindicalista.

Considero que este artículo contribuye con una reflexión novedosa, no solo por la elaboración teórica, epistémica y conceptual del estrés, sino también por el reflejo de su experiencia en un grupo concreto de trabajadoras. La estrategia utilizada en la construcción de esta propuesta puso en juego de manera importante la reflexión a partir de relacionar la observación, la descripción y la triangulación de fuentes de datos, métodos e investigaciones sobre el estrés. Por ello quizá pueda configurarse como un referente relevante ante la ausencia de investigaciones cualitativas sobre el estrés en el mundo de habla hispana, dado que lo que más abunda son investigaciones cuantitativas basadas en modelos unicausales. No obstante, es preciso subrayar que existen avances significativos en el mundo anglosajón, dentro de los que se destacan indagaciones desde la teoría fundamentada que visibilizan diferencias por género y raza; por ejemplo, que muestran la alta significación que pueden tener el racismo y el sexismo, la discriminación y el aislamiento experimentado por mujeres afroamericanas (Hall et al. 2012) ${ }^{38}$. En el terreno metodológico, algunos trabajos presentan un estudio acucioso que apuesta a comprender la expresión del estrés usando aproximaciones cuantitativas y cualitativas para explicar diferencias culturales, ya que el enfoque cualitativo contribuye enormemente a profundizar los resultados cuantitativos y revela, desde evaluaciones realizadas en el ámbito laboral, que hay estresores específicamente culturales que a menudo se pasan por alto en la investigación cuantitativa (Liu, Spector y Shi 2008). Estas observaciones impulsan la investigación sobre estrés laboral intercultural con diversos grupos de trabajadores. Otros autores se han centrado en un estado del arte sobre la investigación cualitativa acerca del estrés laboral y el estrés escolar (Hurts, Baranik y Daniel 2012; Mazzola, Schonfeld y Spector 2011) y han mostrado los enormes beneficios de dicha investigación, porque logra profundidad, atiende a una perspectiva diferencial por género y etnia y otras categorías demográficas, destaca los factores socioculturales implicados en el estrés, y contribuye a la generación de hipótesis que forjan nueva investigación. Para su ámbito de revisión, estos autores concluyen que, aunque la investigación cualitativa es un método valioso y la aplicación de métodos mixtos es todavía más eficaz, aún no se han convertido en una tendencia generalizada para la indagación del estrés ocupacional. 
Desde mi perspectiva, la propuesta desarrollada aquí podrá impulsar nuevas rutas de indagación en el mundo hispano.

\section{Referencias}

Balka, Ellen. 1995. “Technology as a Factor in Women's Occupational the Case Stress. Of Telephone Operators”. En Invisible. Issues in Women's Occupational Health, editado por Elsie Taylor, Barbara Neis, Karen Messing y Lucie Dumais, 75-103. Charlottetown, CA: Gynergy Books.

Baron, Reuben M. y Daniel A. Kenny. 1986. "The Moderator Mediator Variable Distinction in Social Psychological Research. Conceptual, Strategic, and Statistical Considerations”. Journal of Personality and Social Psychology 51: 1173-1182. https://www.ncbi.nlm.nih.gov/ pubmed/3806354

Brief, Arthur P. y Walter R. Nord. 1990. "Work and Meaning: Definitions and interpretations”. En Meanings of Occupational Work: A Collection of Essays, editado por Arthur Brief y Walter Nord, 1-19. Lexington, MA: Lexington Books.

Brown, George y Tirril Harris. 1978. Social Origins of Depression: A Study of Psychiatric Disorder in Women. Nueva York: Free Press.

Cedillo, Leonor y Robert Karasek. 2001. "Reliability and Validity of the Spanish Version of the Job Content Questionnaire among Mexican Women Workers”. www.jcqcenter.org

Denzin, Norman K. 1989. Interpretative Interactionism. Newbury Park: Sage.

Dressler, William. 1996. “Culture, Stress, and Disease”. En Medical Anthropology Contemporary Theory and Method, editado por Carolyn Sargent y Thomas Johnson, 248-328. Londres: Greenwood Press.

Durkheim, Émile. (1897) 1976. El suicidio. Madrid: Akal.

Eckenrode, John y Susan Gore. 1990. "Stress between Work and Family. Summary and Conclusions”. En Stress between Work and Family, editado por John Eckenrode y Susan Gore, 205-218. Nueva York: Plenum.

Folkman, Susan y Richard S. Lazarus. 1986. "Stress Processes and Depressive Symptomatology”. Journal of Abnormal Psychology 95 (2): 107-113. https://www.ncbi.nlm.nih.gov/ pubmed/3711433

Geertz, Clifford. 1984 “'From the Native’s Point of View': On the Nature of Anthropological Understanding”. En Culture Theory: Essays on Mind, Emotion and Self, editado por Richard A. Shweder y Robert Levine, 123-136. Cambridge: Cambridge University Press.

Gottlieb, Benjamin H. 1997. Coping with Chronic Stress. Nueva York: Plenum.

Huberman, A. Michael y Matthew B. Miles. 1994. "Data Management and Analysis Methods”. En Handbook of Qualitative Research, editado por Norman K. Denzin e Yvonna Sessions Lincoln, 428-444. Thousand Oaks: Sage. 
Hurts, Carrie, Lisa Baranik y Francis Daniel. 2012. "College Student Stressors: A Review of the Qualitative Research". Stress and Health: Journal of the International Society for the Investigation of Stress 29 (4): 275-285. https://doi.org/10.1002 / smi.2465

Kohn, Melvin L. 1995. "Social Structure and Personality through Time and Space”. En Examining Lives in Context: Perspectives on the Ecology of Human Development, editado por Phyllis Moen, Glenn H. Elder, Jr. y Kurt Luscher, 141-168. Washington: American Psychological Association.

Lara, M. Asunción, Maricarmen Acevedo, Elsa Karina López y Marisa Fernández. 1993. "La salud emocional y las tensiones asociadas con los papeles de género en las madres que trabajan y en las que no trabajan”. Salud Mental 16 (2): 13-23.

Laurell, Asa Cristina y Margarita Márquez. 1983. El desgaste obrero en México. Ciudad de México: ERA.

Laurell, Asa Cristina y Mariano Noriega. 1989. Manual. Conocer para cambiar. Estudio de la salud en el trabajo. Ciudad de México: Universidad Autónoma Metropolitana.

Lazarus, Richard S. 1999. Stress and Emotion. A New Synthesis. Nueva York: Springer Publishing Company.

Liu, Cong, Paul Spector y Lin Shi. 2008. "Use of Both Qualitative and Quantitative Approaches to Study Job Stress in Different Gender and Occupational Groups”. Journal of Occupational Health Psychology 13 (4): 357-370. https://doi.org/10.1037/1076-8998.13.4.357

Lowe, Graham S. y Herbert Northcott. 1993. Stressful Working Conditions and Union Dissatisfaction. Kingston, ON: Queen's University IRC.

Mazzola, Joseph J., Irvin Sam Schonfeld y Paul E. Spector. 2011. "What Qualitative Research Has Taught us about Occupational Stress”. Stress \& Health 27 (2): 93-110. https://doi. org/10.1002/smi.1386

Pearlin, Leonard, I. 1983. "Role Strains and Personal Stress”. En Psychosocial Stress: Trends in Theory and Research, editado por Howard B. Kaplan, 3-32. Nueva York: Academic.

-. 2010. "The Life Course and the Stress Process: Some Conceptual Comparisons". The Journals of Gerontology. Series B: Psychological Sciences and Social Sciences 65B (2): 207-215. http://doi.org/10.1093/geronb/gbp106

Pearlin Leonard I. y Marilyn McKean. 1996. "Stress and the Life Course: A Paradigmatic Alliance”. The Gerontologist 36 (2): 239-247. https://doi.org/10.1093/geront/36.2.239

Peiró, José María, Vicente González-Romá, José Luis Meliá y María Antonia Zalbidea. 1992. "Estrés de rol y bienestar psicológico en el trabajo”. En Influencias sociales y psicológicas en la salud mental, compilado por José L. Álvaro, José R. Torregrosa y Alicia Garrido, 121-142. Madrid: Siglo XXI.

Perry-Jenkins, Maureen, Rena L. Repetti y Ann C. Crouter. 2000. "Work and Family in the 1990's”. Journal of Marriage and the Family 62: 981-998.

Ramírez, Josefina. 2005a. "El estudio del estrés. Un modelo para armar”. Estudios de Antropología Biológica XII: 497-520. http://www.revistas.unam.mx/index.php/eab/article/ view/19080 
—. 2005b. "Representaciones del estrés y su invisibilidad para la atención”. Revista Cuicuilco 12 (33): 27-60. http://www.revistacuicuilco.enah.edu.mx/revista/node/5

—. 2007a. "Estresadas, deprimidas o embrujadas. O de cómo un grupo de operadoras telefónicas se representa su malestar laboral actual”. Estudios de Antropología Biológica XIII: 649-673. http://www.revistas.unam.mx/index.php/eab/article/view/26409

—. 2007b. "La paradoja del trabajo. Un mundo de pérdida y ganancia que refiere el estudio del estrés con un grupo de operadoras telefónicas”. Dimensión Antropológica 41: 137-169.

—. 2008. "Una mirada antropológica sobre el estudio del estrés laboral desde diferentes áreas temáticas y tendencias analíticas”. En Psicología de la salud ocupacional en México, editado por J. F. Uribe Prado, 325-354. Ciudad de México: UNAM.

-. 2010. El estrés como metáfora. Estudio antropológico con un grupo de operadoras telefónicas. Ciudad de México: Conaculta-INAH.

—. 2011a. "Relevancia de la epidemiología sociocultural en el ámbito laboral. Una reflexión a partir del estudio del estrés entre un grupo de operadoras telefónicas”. En Epidemiología sociocultural. Un diálogo en torno a su sentido, métodos y alcances, editado por Jesús Armando Haro, 307-347. Buenos Aires: Lugar.

—. 2011b. "Estrés y emoción entre un grupo de operadoras telefónicas”. Rivista della Societá Italiana di Antropologia Medica: 343-364.

-. 2012. "Cuerpo y emociones. Un nuevo horizonte para la comprensión del sujeto en antropología física”. Diario de Campo 10: 22-27. http://mediateca.inah.gob.mx/repositorio/islandora/object/articulo\%3A11615

-. 2014a. "Construcción social del estrés. Definiciones, indefiniciones y factores explicativos”. En Organización social del trabajo en la posmodernidad. Salud mental, ambientes laborales y vida cotidiana, coordinado por Norma González, 53-90. Ciudad de México: Red Clacso; Universidad Autónoma del Estado de México.

-. 2014b. "Vigilancia, disciplina, nuevos ritmos de trabajo y malestar psicoemocional en un grupo de operadoras telefónicas”. En Transformaciones en el mundo del trabajo: retos actuales, perspectivas a futuro, compilado por Adriana Martínez, Octavio Maza, Redi Gómez y Juan José Morales, 1892-1917. Aguascalientes: Ediciones AMET.

Repetti, Rena L. y Darby Saxbe. 2009. "The Effects of Job Stress on the Family: One Size Does Not Fit All”. En Handbook of Families \& Work: Interdisciplinary Perspectives, editado por D. Russell Crane y Edward Jeffrey Hill, 62-78. Nueva York: University Press of America.

Selye, Hans. 1976. The Stress of Life. Nueva York: McGraw-Hill.

Wheaton, Blair. 1990. "Where Work and Family Meet Stress across Social Roles”. En Stress between Work and Family, editado por John Eckenrode y Susan Gore, 153-174. Nueva York: Plenum Press.

Young, Allan. 1980. "The Discourse on Stress and the Reproduction of Conventional Knowledge”. Social Science \& Medicine 14B: 133-146. https://doi.org/10.1016/0160-7987(80)90003-4 